\title{
Faktor Yang Berpengaruh pada Produksi dan Pendapatan Stroberi di Desa Pandanrejo, Kecamatan Bumiaji, Kota Batu
}

\author{
Zainol Arifin ${ }^{1)^{*}}$, Farah Mutiara ${ }^{2)}$

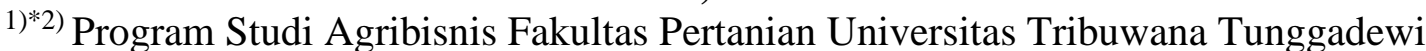 \\ Email :dr.zainolarifin@gmail.com ${ }^{1)^{*}} \underline{\text { fmutiara90@ gmail.com }}^{2)}$
}

\begin{abstract}
Abstrak
Masyarakat Desa Pandanrejo bermata pencaharianpetanidanterletakdisekitar 700-800 meter dariataspermukaan air danteksturtanahnyagembur, dan merupakansalahsatudesawisata yang diunggulkan karena disana mempunya itempat wisata petik strobery. Wisata petik strobery mempunyai peranan dalam membangun perekonomian desa. Hal ini dibuktikan dengan program tanam stroberi dipekarangan rumah. Tujuan penelitian adalah untuk mengetahu ifaktor-faktor yang mempengaruhi produksi dan pendapatan usahatani Stroberi,. Untuk Mengetahui factor pendapatan Usahatani Stroberi. Berdasarkan hasil analisis dan pengujian hipotesis atas FaktorFaktor Yang Mempengaruhi Produksi Usahatani Sari Buah Stroberi, Desa Pandanrejo, Kecamatan Bumiaji, Kota Batu dengan menggunakan analisis Cobb-Douglas maka diketahui bahwa Luas Lahan $\left(\mathrm{X}_{1}\right)$, Umur $\left(\mathrm{X}_{2}\right)$, Modal $\left(\mathrm{X}_{3}\right)$, Tenaga Kerja $\left(\mathrm{X}_{4}\right)$, Pupuk $\left(\mathrm{X}_{6}\right)$,Pendidikan $\left(\mathrm{X}_{7}\right)$ tidak berpengaruh secara signifikan terhadap variabel Produksi $\left(\mathrm{Y}_{1}\right)$, yang artinya tidak memiliki pengaruh yang nyata terhadap faktor produksi. Sedangkan Faktor yang paling berpengaruh secara signifikan yaitu Bibit $\left(\mathrm{X}_{5}\right)$, yang artinya bahwa Bibit memiliki pengaruh yang nyata terhadap Produksi pada Usahatani Sari Buah Stroberi, Desa Pandanrejo, Kecamatan Bumiaji, Kota Batu. Analisis R/C menguntungkan secara ekonomi karena nilai R/C > dari 1. Dengan demikian diketahui bahwa secara ekonomis Usahatani Sari Buah Stroberi, Desa Pandanrejo, Kecamatan Bumiaji, Kota Batu yang dilakukan secara ekonomis menguntungkan, hal ini di buktikan dengan nilai rasio $\mathrm{R} / \mathrm{C}$ sebesar 2,03.
\end{abstract}

Kata Kunci : Produksi, Pendapatan, Usahatani

\section{PENDAHULUAN}

Indonesia adalahnegara agraris dengan yang memiliki kekayaan alam dan hayati sangat banyak dalam bentuk dan variasi. Kondisi agroklimatsangat baik untuk pengembangan berbagai komoditas seperti komoditas tropis dan sub tropis. Masyarakat di Indonesia sendiri sebagian besarbekerjadibidang pertanian terutama masyarakat pedesaan. Salah satu komoditi pertanian yang sering dijumpai dan dikembangkan oleh masyarakat adalah komoditi hortikultura. Jenis tanaman hortikultura sendiri dibagi menjadi beberapa bagian lagi yaitu tanaman buah (Pomologi/Fruti Kultur), Tanaman Sayur (Oleri Kultura), tanaman bunga (Fori
Kultura), dan tanaman obat (Biofarmaka). Jadi dapat di definisikan bahwa tanaman hortikultura merupakan membudidayakan tanaman di kebun. Hal ini memiliki sifat yang lebih intensif yang harus memperhatikan padat modal dan tenaga kerja.

Pandanrejo merupakan desa yang berada di Kecamatan Bumiaji , Kota Batu dan berada di kaki gunung Arjuna dengan ketinggian 700-800 m dpl. Kondisi Desa Pandarejo relatif dingin dengan tekstur tanah yang subur sehingga sebagian masyarakat desa Pandarejo bekerja sebagai petani.

Dengan demikian sektor pertanian yang terdapat di desa Pandarejo sendiri menjadi salah satu sektor yang mempunyai 
ciri khas tersendiri dalam struktur perekonomian di Kota Batu. Sektor pertanian desa Pandarejo memiliki peran penting dalam pembangunan untuk menunjangperekonomian desa. Sebagian besar petani di Desa Pandarejo sebagai petani stroberi dan sayuran. Hal ini dibuktikan dengan program wajib tanam stroberi di pekarangan rumah warga. Hasil panenan sesuai dengan standar kualitas, yang ukuran besar dan baik dijual dalam bentuk segar, sedangkan ukuran yang kecil dan sedikit layu dijual dengan harga murah. Adanya fenomena tersebut membuat warga sekitar mengolah produk stroberi menjadi produk olahan yaitu minuman sari buah stroberi. Hasil olahantersebutlaku dijual di pasaran, namundalam jumlah kecil. Karena produknya tidak bisa bertahan lama. Hal ini disebabkan produk olahan stroberi yang dibuat dengan metode manual, dimana proses penyaringan buah masih menggunakan kainkasa.

$$
\text { Endapan terbentuk karena }
$$
adanyapenyaringan yang tidak sempurna, sehingga berpotensi untuk menimbulkan kontaminasi jamur atau bakteri sehingga produk tidak layak dikonsumsi. Selain itu,agar menghasilkan minuman sari buah yang sehat dan bermutu, mitra ini memberikan bahan pengawet yang dalam jumlah kecil.

Warna buah berubah cepat karena pengaruh fisik sepertipemotongan dan pengaruh sinar matahari. Selain itu, pengaruh biologis (jamur dan bakteri) akan membuat produk menjadi busuk. Oleh karena itu, pengolahan stroberi untuk memperpanjang masa simpannya berperan sangat penting. Stroberidapat diolah menjadi berbagai bentuk minuman. Produk olahan sari buah lebih mudah untuk dicerna dan lebih tahan lama. Kualitas olahan sari buah setara dengan kualitas buahnya. Beberapa faktor penentu kualitas adalah kekentalan, kekeruhan, dan kadar padatan terlarutnya. Pada dasarnya dikenal ada 2 (dua) macam sari buah, yaitu: 1) sari buah encer, yang dapat langsung dikonsumi, 2) sari buah pekat/sirup. Sirup ini tidak dapat langsung diminum, tetapi harus diencerkan dulu dengan air.

Produk minuman olahan hasil mitra sudah dikemas dengan baik dan diberikan label nomor P-IRT. Hal ini menunjukkan bahwa produk olahan sari buah ini telah mempunyai ijin jaminan usaha makanan yang dijual telah memenuhi standar keamanan makanan dan ijin edar produk dari Dinas kesehatan Kota Batu.

Adanya kesadaran masyarakat tentanglabel halal pada produk makanan dan minuman membuat mitra ingin mendapatkan sertifikat halal. Akan tetapi, masih ada kendala yang dihadapi dalam proses sertifikasi. Mitra belum memahami tahapan dan prosedur dalam pengajuan sertifikasi halal.

\section{METODE PENELITIAN}

\section{Waktu Penelitian}

Penelitian stroberi dilakukan di Desa Pandanrejo, Kecamatan Bumiaji, Kota Batu pada 8 Desember 2020 - 1 Januari 2021. Ruang lingkup dalam penelitian ini membahas tentang jenis faktor-faktor yang berpengaruh terhadappendapatan dan produksi Usahatani Sari Buah Stroberi.

\section{Pendekatan Penelitian Dan Tahapan Penelitian}

Pendekatan penelitian diperlukan selama proses kegiatan penelitian Pendekatan yang dilakukan yakni menggunakan deskriptifkuantitatif.Deskriptif kuantitatif merupakan metode pendekatan dengan 
memisahkan masalah yang diselidiki dilokasi penelitian dengan menggambarkan kondisi eksisting. Lahan yang digunakan untuk menanam stroberi disini digunakan lahan milik desa dan masyarakat tani, jumlah karyawan yang dipekerjakan di lumbung stroberi terdapat 30 karyawan.

\section{Teknik Pengambilan Sampel}

Sampel merupakan bagian atau kondisi tertentu yang memiliki ciri khas atau keadaan terte3ntu yang dapat diteliti oleh peneliti dikarenakan tidak semua data atau orang dijadikan sebagai informan sehingga tidak semua orang akan diteliti sehingga digunakan responden.

\section{Metode Analisis Data}

Untuk menganalisis beberapa faktorfaktor yang berpengaruh pada produksi dan pendapatan usahatani sari buah stroberi di Desa Pandarejo, Kota Batu menggunakan fungsi produksi model Cobb douglass dengan rumus:

$$
\begin{aligned}
& \mathrm{Y}=\mathrm{a} \text { o }+\mathrm{X}_{1}{ }^{\mathrm{a} 1} \quad \mathrm{X}_{2}{ }^{\mathrm{a} 2} \quad \mathrm{X}_{3}{ }^{\mathrm{a} 3} \quad \mathrm{X}_{4}{ }^{\mathrm{a} 4} \quad \mathrm{X}_{5}{ }^{\mathrm{a} 5} \\
& \mathrm{X}_{6}{ }^{\mathrm{a} 6} \mathrm{X}_{7}{ }^{\mathrm{a} 7}
\end{aligned}
$$

Model tersebut disederhanakan dengan ditransformasikan ke persamaan regresi linear berganda berbentuk logaritma untuk mempermudah menganalisis data dengan menggunakan aplikasi SPSS 25,

$$
\begin{gathered}
\mathrm{LnY}=\ln \mathrm{a}_{0}+\mathrm{a} 1 \ln \mathrm{X} 1+\mathrm{a} 2 \ln \mathrm{X} 2+\mathrm{a} 3 \ln \mathrm{X} 3+ \\
\mathrm{a} 4 \ln \mathrm{X} 4+\mathrm{a} 5 \ln \mathrm{X} 5+\mathrm{a} 6 \ln \mathrm{X} 6+\mathrm{a} \ln \mathrm{X} 7
\end{gathered}
$$

Keterangan:

$\mathrm{a}_{\mathrm{o}}=$ Konstanta

$\mathrm{a}_{1-7}=$ Koefisien regresi dari masing-masing faktor produksi

$\mathrm{Y}=$ Pendapatan usahatani stroberi (Rp/musim tanam)

$\mathrm{X}_{1}=$ Luas lahan $(\mathrm{Ha})$

$\mathrm{X}_{2}=\operatorname{Umur}(\mathrm{Thn})$

$$
\begin{aligned}
& \mathrm{X}_{3}=\text { Tenaga kerja }(\mathrm{HOK}) \\
& \mathrm{X}_{4}=\operatorname{Bibit}(\mathrm{Kg}) \\
& \mathrm{X}_{5}=\operatorname{Pupuk}(\mathrm{Kg}) \\
& \mathrm{X}_{6}=\operatorname{Modal}(\mathrm{Rp}) \\
& \mathrm{X}_{7}=\operatorname{Pendidikan}(\mathrm{Pd})
\end{aligned}
$$

Idak ada uji validias dan reliabel $\mathrm{Hal}$ ini dikarenakan dalam pengujian dengan analisis Cobb-Douglas, Data ditransfer ke bentuk linear dengan cara melogaritmakan angka-angka yang diperoleh dari hasil penelitian, sehingga angka yang digunakan berbentuk Logaritma Natural (Ln). Sehingga dalam pengujian Validitas dan Reliabilitas ditiadakan, dimana peneliti menggunakan acuan dari Hasil Uji Asumsi Klasik Yaitu Uji Normalitas, Uji Heterosekdastisitas, dan Uji Multikolinearitas. Apabila data terdistribusi secaranormal, maka tidak terjadi heteroskedastisitas antar variabel, Serta tidak terjadi gejala Multikolinearitas maka data layak untuk dianalisis.

\section{Uji Asumsi Klasik}

Menurut Kasenda (2013), uji asumsi klasik dilakukan sebelum melakukan model model persamaan Cobb Douglas. Jika sudah terpenuhi maka model regresi tersebut dapat digunakan untuk uji hipotesis. Sebelum mengetahui model regresi Cobb Douglas memenuhi asumsi klasik, perlu adanya pengujian dengan uji asumsi klasik yang diantaranya adalah:

\section{a) Uji Normalitas}

Uji yang dilakukan untuk mengetahui apakah nilai residual terdistribusi normal atau tidak. Model regresi disebut baik jika nilai residual berdistribusi normal atau mendekati normal Normalitas diuji dengan model Kolmogorov-smirnov dengan aplikasi SPSS 25. Dalam uji normalitas dasar pengambilan keputusannya adalah: 
a) Saat signifikansi lebih dari 0,05, maka berdistribusi normal.

b) Saat signifikansi kurang dari 0,05, maka tidak berdistribusi normal.

\section{b) Uji Multikolinearitas}

Digunakan untuk mengetahui gejala korelasi yang tinggi antara variabel dalam model Cobb Douglas. Ketika terjadi gejala keterikatan variabel yang tinggi antara variabel bebas (faktor-faktor produksi usahatani stroberi) dengan variabel terikatnya (hasil produksi dan pendapatan) menyebabkan hubungan keduanya menjadi terganggu. Dalam penelitian ini uji multikolinearitas dilakukan dengan aplikasi SPSS 25. Dasar penentuan keputusan uji ini adalah tolerance dan VIF, dengan syarat ketentuan masing-masing adalah

1) Penentuan keputusan berdasarkan nilai tolerance

a) saat nilai toleransi lebih (>) 0,10 maka tidak terjadi multikolinearitas dalam model regresi.

b) Jika nilai toleransi kurang $(<)$ 0,10 maka terjadi multikolinearitas dalam model regresi.

2) Pedoman penentuan keputusan berdasarkan nilai VIF (variance inflation factor)

a) Jika nilai VIF kurang dari 10,00 maka tidak terjadi multikolinearitas dalam model regresi Cobb Douglas

b) Jika nilai VIF lebih dari 10,00 maka terjadi multikolinearitas dalam regresi Cobb Douglas

c) Uji Heteroskedastisitas

Digunakan untuk melihat ketidaksamaan varians dari residual suatu penelitian ke penelitian lainnya. Model regresi Cobb Dounglas yang baikharus bisa memenuhi syarat adalah adanya homoskedasitas (kesamaan varians dari suatu faktor ke faktor lainnya).
Dalam penelitian ini uji heteroskedastisitas dilakukan dengan uji glesjer pada aplikasi SPSS. Adapun dasar pengambilan keputusan dalam uji glesjer adalah sebaagai berikut:

1) Saat nilai signifikansi lebih dari (>) 0,05, maka tidak terjadi gejala heteroskedastisitas dalam model regresi Cobb Douglas.

2) Saat nilai signifikansi (sig.) kurang dari 0,05, maka terjadi gejala heteroskedastisitas dalam model regresi Cobb Douglas.

\section{Pengujian Hipotesis}

1) Uji $F$

Uji $F$ dalam penelitian analisis faktor-faktor yanb berpengaruh dipakai untuk melihat sejauh mana variabel produksi maupun pendapatan signifikan atau tidak terhadap variabel lahan,tenaga kerja,pupuk,bibit. Hasil perhitungan uji signifikansi digunakan kriteria sebagai berikut :

a) Bila Signf. Kurang dari $\alpha$ maka Ho ditolak

b) Bila Signf. Lebih dari a maka Ho diterima

\section{2) Uji R-Square}

$\mathrm{R}$-square $\left(\mathrm{R}^{2}\right)$ dipakai melihat sejauh manapengaruh variabel bebas terhadap variabel dependen (y), nilai residualnya dipengaruhi oleh variabel bebas (x) yang tidak masuk model.

3) Uji t

Uji t dipakai melihat sejauh mana variabel produksi dan pendapatan signifikan terhadap variabel lahan, bibit, pupuk secara parsial untuk setiap variabel. Setelah mendaoatkan nilai t-hitpada tiap variabel independen, maka ketentuan yang digunakan adalah :

Jika thitunglebih dari tabel, maka Ho ditolak dan hubungan variabel signifikan 


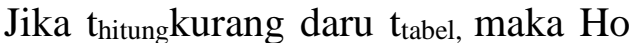
diterima dan hubungan variabel tidak signifikan

\section{HASIL DAN PEMBAHASAN}

\section{A. Faktor-Faktor yang Mempengaruhi ProduksiStroberi}

Faktor-faktor yang mempengaruhi produksi pada Usahatani Sari Buah Stroberi, Pandanrejo, Kecamatan Bumiaji, Kota Batu terdiri dari, Luas Lahan $\left(\mathrm{M}^{2}\right)$, Umur (Tahun), Tenaga kerja (Hok), Bibit (Kilo Gram), Pupuk (Kilo Gram), Modal (Rupiah), Pendidikan(Pd) Adapun uraian dari variabel-variabel yang mepengaruhi produksi yaitu sebagai berikut:

\section{Luas Lahan (Ha)}

Lahanmenjadi faktor kunci dalam usahatani stroberi di DesaPandanrejo, Kota Batudan menjadi faktor yang tetap dibandingkan dengan faktor produksi lain sehingga penggunaannya haus efieisn.

\section{Umur (Thn)}

Umur adalah usia responden yang mengeolah usahatani sari buah sroberi. Umur lamanya berusahatani di hitung dari awal petani memulai bertani sampai sekarang. Sedangkan untuk defenisi umur sendiri yaitu usia seseorang yang di mulai dari semenjak dilahirkan sampai kehidupannya berlangsung saat sekarang.

\section{Modal (Rp)}

Modal

dalamushatanistroberimeruapakanbarang atau uanag dengan faktor produksi lain dan tenaga kerja untuk menghasilkan produksi pertanian.

\section{Tenaga kerja (HOK)}

Dalampenelitianstroberiiniada3macam tenaga kerja yakni manusia, ternak, dan mekanik.

Dalampenelitianinidigunakantenagakerjama nusia yang volume kegiatandihitungdengan HOK (Hari orang kerja). Tenaga kerja wanita Rp. 35.000 per hari dan tenaga kerja pria sebesar Rp 50.000/hari.

\section{Bibit (Kg)}

Bibit termasuk yang berpengaruh terhadap pendapatan, secara parsial bibit berpengaruh nyata dalam pendapatan petani, baik dari kualitas bibit maupun jumlah bibit yang digunakan petani. Bibit akan menentukan baik buruknya proses tanaman berkembang. Sehingga semakin baik kualitas bibit yang digunakan oleh petani maka, akan berpengaruh terhadap tanaman dan hasil panen.

\section{Pupuk (Kg)}

Pupuk berpengaruh terhadap pendapatan petani, karena pertumbuhan tanaman akan di tentukan pupuk yang di berikan, pupuk yang terlalu banyak akan berpengaruh terhadap produksi jangka panjang. pupuk yang baik di gunakan untuk tanaman yaitu pupuk yang sesuai anjuran dinas pertanian baik pupuk kimia maupun pupuk kompos dan organik.

\section{Pendidikan (Pd)}

Pendidikan diukur sesuai jenjang yang akan di tempuhnya dalam melanjutkan pendidikan yang ditempuh .Pendidikanmeliputi TK, SD, SMP, SMA. Perguruan Tinggi

\section{B. Hasil Asumsi Klasik Faktor Yang Mempengaruhi Produksi}

1. Uji Normalitas

Hasil uji normalitas pada penelitian factor produksistroberi dilakukan dengan K0lmogorov - Smirnov.Berikut ini disajikan hasil dari pengujian normalitas sebagai berikut:

Tabel 1. Hasil Uji Normalitas

Gambar 1. normal probability plot 


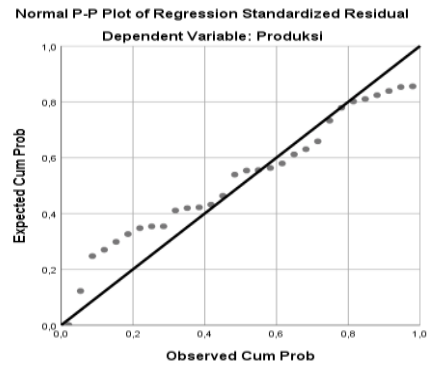

Sumber: Data Primer, Diolah 2021

$\mathrm{Gb}$ 1. menyatakan n1lai Asymp. Sig.(2-tailed) sebesar 0.200 . karenanilaiAsymp Siglebihdari 0,05. maka dapat dinyatakan data yang digunakan dalam

\begin{tabular}{|c|c|c|}
\hline Variabel & VIF & Keterangan \\
\hline & & Tidak Terjadi \\
\hline Luas Lahan & 1,270 & $\begin{array}{c}\text { Multikolinieritas } \\
\text { Tidak Terjadi }\end{array}$ \\
\hline Umur & 1,201 & $\begin{array}{l}\text { Multikolinieritas } \\
\text { Tidak Terjadi }\end{array}$ \\
\hline Modal & 1,250 & Multikolinieritas \\
\hline Tenaga & & Tidak Terjadi \\
\hline Kerja & 1,464 & $\begin{array}{c}\text { Multikolinieritas } \\
\text { Tidak Terjadi }\end{array}$ \\
\hline Bibit & 1,267 & $\begin{array}{l}\text { Multikolinieritas } \\
\text { Tidak Terjadi }\end{array}$ \\
\hline Pupuk & 1,068 & $\begin{array}{c}\text { Multikolinieritas } \\
\text { Tidak Terjadi }\end{array}$ \\
\hline Pendidikan & 1,085 & Multikolinieritas \\
\hline
\end{tabular}

Sumber: Data Primer, Diolah 2021

Berdasarkan tabel 1variabel Luas Lahan, Umur,Modal, Tenaga Kerja, Bibit, Pupuk, Pendidikantidak terjadi multikolinieritas. Hal inidikarenakan saat VIF < 10. Dapat disimpulkan bahwa antara variabel bebas tidak saling mempengaruhi atau tidak terjadi multikolinieritas. Hal ini menjelaskan bahwa Luas Lahan, Umur,Modal, Tenaga Kerja, Bibit, Pupuk, Pendidikan dapat dilanjutkan dan digunakan untuk analisis selanjutnya.

2. Uji Heteroskedasitas

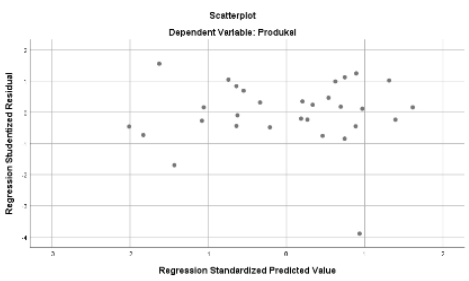

Sumber: Data Primer, Diolah 2021

Berdasarkan gambar

8. Menunjukkan bahwa titik-titik pada scatter plot menyebar di atas dan di bawah angka nol sumbu Y, sehingga disimpulkan tidak ada heteroskedastisitas dalam model regresi pada penelitian ini.

Gambar 2.Scatter Plot 
2. Pengujian Hipotesis Faktor Yang Mempengaruhi Produksi

1. Uji R-Square

Koefisiensi determinasi memiliki fungsi untuk mengetahui besarnya variasivariabel Luas Lahan, Umur, Modal, Model Summary

\begin{tabular}{ccccc}
\hline Model & $\mathrm{R}$ & $\mathrm{R}$ Square & $\begin{array}{c}\text { Adjusted } \mathrm{R} \\
\text { Square }\end{array}$ & $\begin{array}{c}\text { Std. Error of the } \\
\text { Estimate }\end{array}$ \\
\hline 1 &, $878^{\mathrm{a}}$ &, 771 &, 698 &, 13134 \\
\hline
\end{tabular}

a. Predictors: (Constant), Pendidikan, Umur, Modal, Luas lahan, Pupuk, Bibit, Tenaga Kerja

b. Dependent Variable: Produksi

Sumber: Data Primer, Diolah 2021

Hasiluji koefisien determinasi pada tabel 2 menjelaskan nilai R Square adalah 0,878 . hal ini menunjukkan bahwa $87,8 \%$ variabel Produksi dipengaruhi oleh Variabel Luas Lahan, Umur, Modal, Tenaga Kerja, Bibit, Pupuk, Pendidikan. Nilai 12,2\% diterangkan variabel yang lain di luarpenelitian.
Tenaga Kerja, Bibit, Pupuk, Pendidikan terhadap variabel dependen Produksi. Dari hasil pengujian dengan menggunakan SPSS 25 dapat dilihat nilai koefisiensi determinasi.

Tabel 2. Hasil Uji R-Square

ANOVA $^{a}$

\begin{tabular}{|c|c|c|c|c|c|c|}
\hline Model & & $\begin{array}{c}\text { Sum of } \\
\text { Squares }\end{array}$ & $\mathrm{df}$ & $\begin{array}{l}\text { Mean } \\
\text { Square }\end{array}$ & f & Sig. \\
\hline \multirow[t]{3}{*}{1} & $\begin{array}{l}\text { Regressio } \\
\mathrm{n}\end{array}$ & 1,277 & 7 & , 182 & 10,578 &, $000^{\mathrm{b}}$ \\
\hline & Residual & ,379 & 22 & ,017 & & \\
\hline & Total & 1,657 & 29 & & & \\
\hline
\end{tabular}

a. Dependent Variable: Produksi

b. Predictors: (Constant), Pendidikan, Bibit, Umur, Pupuk, Modal, Luas lahan, Tenaga Kerja

Sumber: Data Primer, Diolah 2021

Berdasarkan tabel 3 diatas diketahui Nilai $f_{\text {hitung }}$ sebesar 10,578 dengan tingkat signifikansi $0,000<0,05$. Hal ini berarti bahwa semua variabel bebas (Luas Lahan, Umur, Modal, Tenaga Kerja, Bibit, Pupuk,

Pendidikan) secara bersama-sama mampu mempengaruhi variabel terikat (Produksi) secara signifikan.

3. Uji t

Tabel 4. Hasil Uji t

\begin{tabular}{cccc}
\hline Variabel & $\boldsymbol{\beta}$ & thitung & Signifikansi \\
\hline Konstanta & 7,091 & 3,998 & 0,000
\end{tabular}




\begin{tabular}{lccc}
$\mathrm{X}_{1}=$ Luas Lahan & 0,001 & 0,009 & 0,993 \\
$\mathrm{X}_{2}=$ Umur & 0,073 & 1,167 & 0,256 \\
$\mathrm{X}_{3}=$ Modal & $-0,109$ & $-0,964$ & 0,345 \\
$\mathrm{X}_{4}=$ Tenaga Kerja & 0,035 & 0,911 & 0,372 \\
$\mathrm{X}_{5}=$ Bibit & 0,927 & 7,132 & 0,000 \\
$\mathrm{X}_{6}=$ Pupuk & 0,138 & 1,318 & 0,201 \\
$\mathrm{X}_{7}=$ Pendidikan & $-0,055$ & $-1,557$ & 0,134 \\
\hline
\end{tabular}

R-Square 0,878

$\mathrm{f}_{\text {hitung }} 10,578$

0,000

$\mathrm{f}_{\text {tabel }} 2,44$

$t_{\text {tabel }} 2,068$

Sumber: Data Primer, Diolah 2021

Berdasarkan uji t pada tabel 4 dapat dilihat koefisien untuk persamaan regresi dalam penelitian ini yang dapat disusun dalam persamaan matematis sebagai berikut:

$\mathrm{Y}_{1}=7,091+0,001 \mathrm{X}_{1}+0,073 \mathrm{X}_{2}+-$ $\mathbf{0 , 1 0 9}_{3}+0,035 X_{4}+0,927 X_{5}+0,138 X_{6}+-$ $0,0,055 X_{7}+e$

Berdasarkan hasil pengujian diatas maka adapun interpretasi dari setiap variabel bebas pada model dapat dijelaskan sebagai berikut:

$\alpha=$ Diketahui bahwa nilai konstanta positif sebesar 7,091 menunjukkan bahwa tanpa adanya pengaruh variabel bebas Luas Lahan $\left(\mathrm{X}_{1}\right)$, Umur $\left(\mathrm{X}_{2}\right)$, Modal $\left(\mathrm{X}_{3}\right)$, Tenaga Kerja $\left(\mathrm{X}_{4}\right)$, Bibit $\left(\mathrm{X}_{5}\right)$, Pupuk $\left(\mathrm{X}_{6}\right)$, Pendidikan $\left(\mathrm{X}_{7}\right)$, maka variabel terikat Produksi $\left(\mathrm{Y}_{1}\right)$, akan meningkatkan produksi petani di Usahatani Sari Buah Stroberi, Desa Pandanrejo, Kecamatan Bumiaji, Kota Batu sebesar 7,091 Kg.

\section{Luas Lahan $\left(\mathrm{X}_{1}\right)$}

Luas lahan memiliki nilai koefisien sebesar 0,001. Hal ini berarti setiap penambahan $1 \mathrm{M}^{2}$ luas lahan akan meningkatkan hasil produksi stroberi sebesar $1 \%$. Nilai dari $t_{\text {hitung }}<t_{\text {tabel }}$ yaitu $0,009<2,068$ dengan signifikansi sebesar $0,993>0,05$, yang berarti bahwa Variabel Luas Lahan $\left(\mathrm{X}_{1}\right)$ tidak berpengaruh signifikan terhadap Variabel Produksi ( $\left.\mathrm{Y}_{1}\right)$.

\section{2. $\operatorname{Umur}\left(\mathrm{X}_{2}\right)$}

Umur memiliki nilai koefisien sebesar 0,073. Hal ini berarti setiap bertambahnya umur petani 1 tahun akan berpengaruh terhadap faktor produksi dan mengurangi produksi sebesar $7,3 \%$. Nilai dari thitung < ttabel yaitu $1,167<2,068$ dengan signifikansi sebesar 0,256>0,05, yang berarti bahwa Variabel Umur $\left(\mathrm{X}_{2}\right)$ tidak berpengaruh secara signifikan terhadap Variabel Produksi ( $\left.\mathrm{Y}_{1}\right)$

\section{Modal $\left(\mathrm{X}_{3}\right)$}

Modal memiliki nilai koefisien sebesar 0,109. Hal ini berarti bahwa dengan pengurangan modal Rp 1 akan mengurangi produksi stroberi sebesar $10,9 \%$. Nilai dari thitung < ttabel yaitu $-0,964<2,068$ dengan signifikansi sebesar 0,345>0,05, yang berarti bahwa variabel modal $\left(\mathrm{X}_{3}\right)$ tidak berpengaruh secara signifikan terhadap variabel produksi $\left(\mathrm{Y}_{1}\right)$

4. Tenaga Kerja $\left(\mathrm{X}_{4}\right)$

Tenaga Kerja memiliki nilai koefisien sebesar 0,035. Hal ini berarti setiap penambahan 1 tenaga kerja akan 
meningkatkan hasil produksi stroberi sebesar $3,5 \%$. Nilai dari thitung < tabel yaitu $0,911<2,068$ dengan signifikansi sebesar 0,372>0,05 yang berarti bahwa variabel Tenaga Kerja $\left(\mathrm{X}_{4}\right)$ tidak berpengaruh secara signifikan terhadap Variabel Produksi ( $\left.\mathrm{Y}_{1}\right)$

5. Bibit $\left(\mathrm{X}_{5}\right)$

Bibit memiliki nilai koefisien sebesar 0,927. Hal ini berarti bahwa setiap penambahan bibit 1 Kilo gram akan meningkatkan produksi stroberi sebesar $92,7 \%$. Nilai dari thitung $>$ ttabel yaitu 7,132> 2,068 dengan signifikansi sebesar $0,000<0,05$ yang berarti bahwa Variabel Bibit $\left(\mathrm{X}_{5}\right)$ berpengaruh secara signifikan terhadap Variabel Produksi $\left(\mathrm{Y}_{1}\right)$

6. Pupuk $\left(\mathrm{X}_{6}\right)$

Pupuk memiliki nilai koefisien sebesar 0,138. Hal ini berarti bahwa setiap penambahan pupuk 1 Kilo Gram akan meningkatkan produksi stroberi sebesar $13,8 \%$. Nilai dari thitung < ttabel yaitu $1,318<2,068$ dengan signifikansi sebesar $0,201>0,05$ yang berarti bahwa Variabel Pupuk $\left(\mathrm{X}_{6}\right)$ tidak berpengaruh secara signifikan terhadap Variabel Produksi $\left(\mathrm{Y}_{1}\right)$.

7. Pendidikan $\left(\mathrm{X}_{7}\right)$

Pendidikan memiliki nilai koefisien sebesar -0,055. Hal ini berarti bahwa setiap penambahan 1 Orang akan meningkatkan produksi stroberi sebesar $12,7 \%$. Nilai dari thitung $>$ ttabel yaitu $-1,557<2,068$ dengan signifikansi sebesar 0,134> 0,05 yang berarti bahwa Variabel Pendidikan $\left(\mathrm{X}_{7}\right)$ tidak berpengaruh secara signifikan terhadap Variabel Produksi $\left(\mathrm{Y}_{1}\right)$

\section{a. Faktor-Faktor Yang Mempengaruhi Pendapatan}

Faktor-faktor yang mempengaruhi pendapatan pada Usahatani Sari Buah Stroberi, Desa Pandanrejo, Kecamatan
Bumiaji, Kota Batu terdiri dari,Biaya Bibit (Rp), Biaya Pupuk (Rp), Biaya Pestisida (Rp), Biaya Tenaga Kerja (Rp). Adapun uraian dari variabel-variabel yang mempengaruhi pendapatan yaitu sebagai berikut.

\section{Biaya Bibit $\left(X_{1}\right)$}

Biaya Bibit adalah biaya benih yang harus dikeluarkan petani stroberi di Usahatani Sari Buah Stroberi, Desa Pandanrejo, Kecamatan Bumiaji, Kota Batu untuk kebutuhan produksinya dalam satu musim tanam (Rp).

\section{Biaya Pupuk $\left(\mathrm{X}_{2}\right)$}

Biaya pupuk adalah biaya pupuk yang harus dikeluarkan petani stroberi Usahatani Sari Buah Stroberi, Desa Pandanrejo, Kecamatan Bumiaji, Kota Batu untuk kebutuhan produksinya dalam satu musim tanam (Rp).

\section{Biaya Pestisida $\left(\mathbf{X}_{3}\right)$}

Biaya Pestisida adalah biaya pestisida yang harus dikeluarkan petani stroberi Usahatani Sari Buah Stroberi, Desa Pandanrejo, Kecamatan Bumiaji, Kota Batu untuk kebutuhan produksinya dalam satu musim tanam (Rp).

\section{Biaya Tenaga Kerja $\left(\mathrm{X}_{4}\right)$}

Biaya Tenaga Kerja adalah biaya tenaga kerja yang harus dikeluarkan petani stroberi Usahatani Sari Buah Stroberi, Desa Pandanrejo, Kecamatan Bumiaji, Kota Batu untuk kebutuhan produksinya dalam satu musim tanam (Rp).

\subsection{Uji Asumsi Klasik Faktor Yang Mempengaruhi Pendapatan}

1. Uji Normalitas

Berikut ini disajikan hasil dari pengujian normalitas sebagai berikut: Tabel 9. Hasil Uji Normalitas

\section{One-Sample Kolmogorov-Smirnov Test}




\begin{tabular}{lll}
\hline & & $\begin{array}{l}\text { Unstandar } \\
\text { dized } \\
\text { Residual }\end{array}$ \\
\hline $\mathrm{N}$ & Mean & 30 \\
Normal &, 0000000 \\
Parameters ${ }^{\mathrm{a}, \mathrm{b}}$ & Std. &, 0614870 \\
Most Extreme & Deviation & 0 \\
Differences & Absolute &, 143 \\
& Positive &, 143 \\
Test Statistic & Negative &,- 072 \\
Asymp. Sig. (2-tailed) &, 143 \\
\hline
\end{tabular}

a. Test distribution is Normal.

b. Calculated from data.

Sumber: Data Primer, Diolah 2021

Berdasarkan tabel 9 dapat dilihat bahwa hasil Uji Normalitas menyatakan nilai Asymp. Sig.(2-tailed) sebesar 0.121 > 0,05 dan diketahui bahwa titik-titik pada normal probability plot terkumpul di sekitar garis lurus, sehingga disimpulkan bahwa dalam penelitian ini residual model regresi berdistribusi normal.

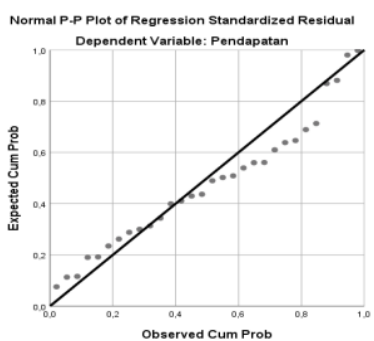

Sumber: Data Primer, Diolah 2021

Tabel 10. Uji Multikolinieritas

Gambar 9. Normal Probability Plot

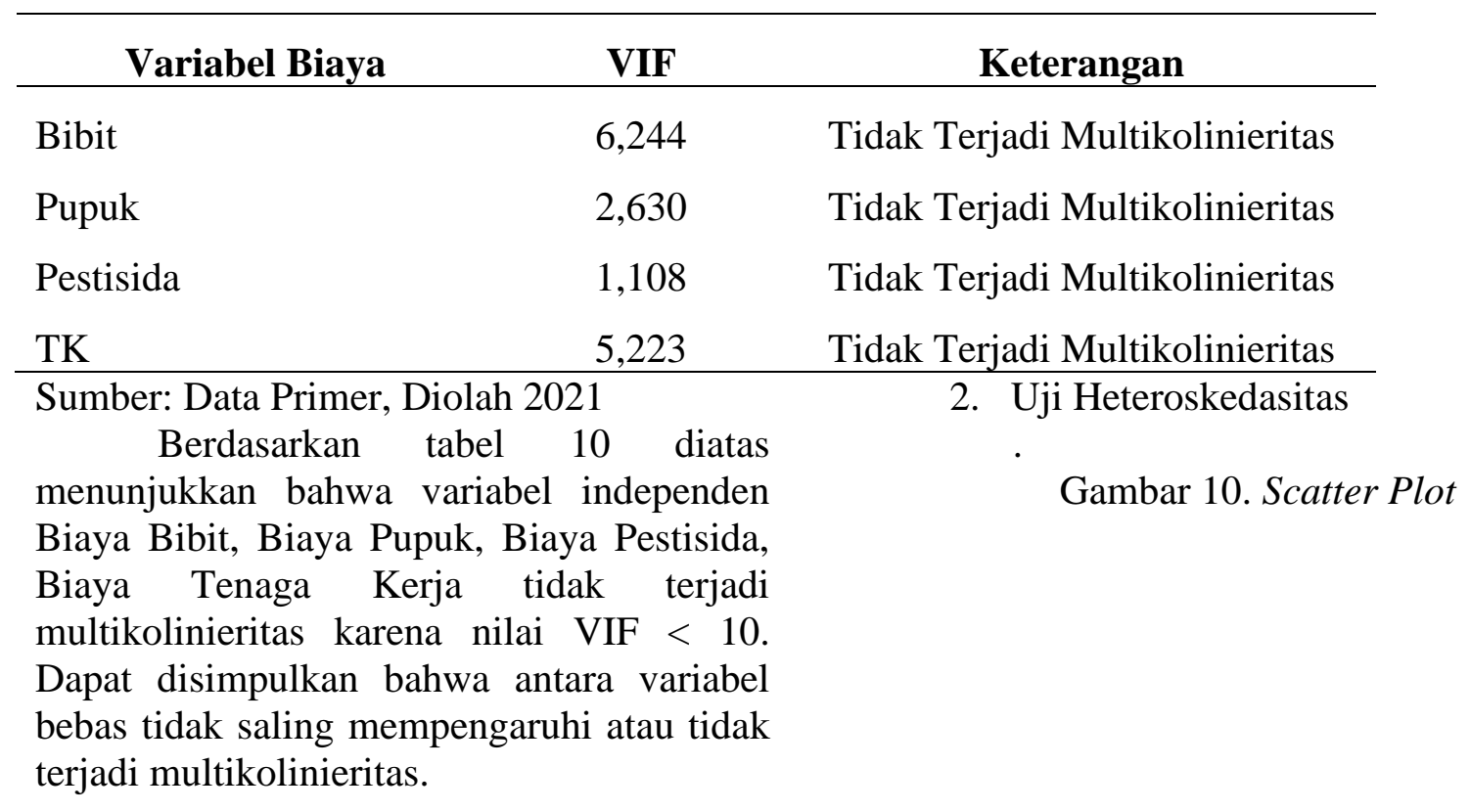




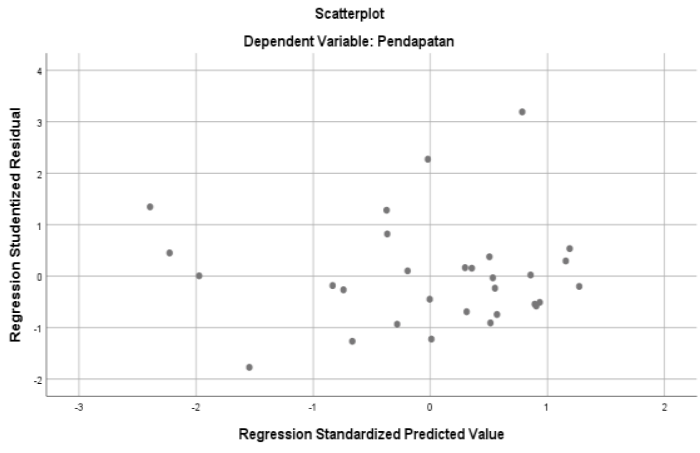

Sumber: Data Primer, Diolah 2021

Berdasarkan gambar 10 menunjukkan bahwa titik-titik pada scatter plot menyebar di atas dan di bawah angka nol sumbu Y, sehingga disimpulkan tidak ada heteroskedastisitas dalam model regresi pada penelitian ini. Artinya bahwa Biaya Bibit, Biaya Pupuk, Biaya Pestisida, Biaya Tenaga Kerja tidak ada heteroskedastisitas dalam model regresi sehingga data pada penelitian ini bebas dari heteroskedastisitas.

\subsubsection{Uji HipotesisFaktor Yang Mempengaruhi Pendapatan}

1. Uji R-Square

Tabel 11. Hasil Uji R-Square

Model Summary ${ }^{b}$

Std.

Error

of the

R Adjusted Estima

\begin{tabular}{lllll} 
Model & $R$ & Square & \multicolumn{2}{c}{$\mathrm{R}$ Square te } \\
\hline 1 &, 94 &, 892 &, 874 &, 0662
\end{tabular}

a. Predictors: (Constant), Biaya Tenaga Kerja, Biaya Pestisida, Biaya Pupuk, Biaya Bibit

b. Dependent Variable: Pendapatan

Sumber: Data Primer, Diolah 2021

Berdasarkan tabel 11 hasil pengujian uji koefisien determinasi pada tabel menjelaskan bahwa besarnya nilai $\mathrm{R}$ Square adalah 0,892 hal ini berarti bahwa 89,3\%

\section{ANOVA $^{\mathrm{a}}$}

\begin{tabular}{|c|c|c|c|c|c|}
\hline & $\begin{array}{l}\text { Sum of } \\
\text { Square }\end{array}$ & & $\begin{array}{l}\text { Mean } \\
\text { Squar }\end{array}$ & & \\
\hline Model & $\mathrm{s}$ & df & $\mathrm{e}$ & $\mathrm{F}$ & Sig. \\
\hline 1 Regressi & & & & 51 & \\
\hline on & 901 & 4 & 225 & $\begin{array}{r}\text { 3 } \\
67\end{array}$ & $0^{\mathrm{b}}$ \\
\hline Residual & ,110 & $\begin{array}{l}2 \\
5\end{array}$ & ,004 & & \\
\hline Total & 1,011 & $\begin{array}{l}2 \\
9\end{array}$ & & & \\
\hline
\end{tabular}

a. Dependent Variable: Pendapatan

b. Predictors: (Constant), Biaya Tenaga Kerja, Biaya Pestisida, Biaya Pupuk, Biaya Bibit variabel Pendapatan dipengaruhi oleh Variabel Biaya Bibit, Biaya Pupuk, Biaya Pestisida, Biaya Tenaga Kerja sedangkan sisanya sebesar $10,8 \%$ dijelaskan oleh variabel lain yang tidak termasuk dalam penelitian ini.

2. Uji F

Tabel 12. Hasil Uji F 
Sumber: Data Primer, Diolah 2021

nilai F-hitung sebesar 51,367 dengan tingkat signifikansi $0,000<0,05$. Hal ini berarti bahwa semua variabel bebas (Biaya Bibit, Biaya Pupuk, Biaya Pestisida, Biaya
Tenaga Kerja) secara bersama-sama mampu mempengaruhi variabel terikat (Pendapatan) secara signifikan.

\section{Uji T}

Tabel 13. Hasil Uji t

\begin{tabular}{lccc}
\hline Variabel & & thitung & Signifikansi \\
\hline Konstanta & 8,442 & 7,311 & 0,000 \\
X1=Biaya Bibit & 0,295 & 2,042 & 0,052 \\
X2= Biaya Pupuk & 0,076 & 1,568 & 0,129 \\
X3= Biaya Pestisida & 0,011 & 0,331 & 0,743 \\
X4= Biaya Tenaga Kerja & 0,149 & 3,291 & 0,003 \\
\hline R-Square 0,892 & & & 0,000 \\
$\mathrm{f}_{\text {hitung } 51,367}$ & & \\
$\mathrm{f}_{\text {tabel }}$ 2,74 & & \\
$\mathrm{t}_{\text {tabel }}$ 2,055 & & \\
\hline Sumber: & & \\
\hline
\end{tabular}

Sumber: Data Primer, Diolah 2021

Secara matematis, persamaannya sebagai berikut:

\section{$Y_{1}=8,442+0,295 X_{1+0,076} X_{2+-}$ $0_{11} X_{3}+0,149 X_{4}+e$}

Berdasarkan hasil pengujian diatas maka adapun interpretasi dari setiap variabel bebas pada model dapat dijelaskan sebagai berikut:

$\alpha=$ Diketahui bahwa nilai konstanta positif sebesar 8,442 menunjukkan bahwa tanpa adanya pengaruh variabel Biaya Bibit $\left(\mathrm{X}_{1}\right)$,Biaya Pupuk $\left(\mathrm{X}_{2}\right)$,Biaya Pestisida $\left(\mathrm{X}_{3}\right)$,Biaya Tenaga Kerja $\left(\mathrm{X}_{4}\right)$, maka variabel terikat Pendapatan $\left(\mathrm{Y}_{2}\right)$. Maka akan meningkatkan Pendapatan petani di Usahatani Sari Buah Stroberi, Desa Pandanrejo, Kecamatan Bumiaji, Kota Batu sebesar Rp 8.442.000.

1. Biaya Bibit $\left(\mathrm{X}_{1}\right)$

Biaya bibit memiliki nilai koefisien sebesar 0.295. Hal ini berarti setiap penambahan Rp. 1 maka akan meningkatkan pendapatan Petani Stroberi sebesar 2.950. Nilai dari thitung < ttabel yaitu $2.042<2.055$ dengan signifikansi sebesar 0.052>0.05 yang berarti bahwa variabel biaya bibit tidak berpengaruh secara signifikan terhadap pendapatan petani stroberi.

2. Biaya Pupuk $\left(\mathrm{X}_{2}\right)$

Biaya pupuk memiliki nilai koefisien sebesar 0,076. Hal ini berarti setiap penambahan Rp 1 maka akan meningkatkan pendapatan Petani Stroberi sebesar Rp 760. Nilai dari thitung < ttabel yaitu $1,568<2,055$ dengan signifikansi sebesar 0,129>0,05 yang berarti bahwa variabel biaya pupuk tidak berpengaruh secara signifikan terhadap pendapatan petani stroberi.

3. Biaya Pestisida $\left(\mathrm{X}_{3}\right)$

Biaya pestisida memiliki nilai koefisien sebesar0,011. Hal ini berarti setiap penambahan $\mathrm{Rp} 1$ maka akan meningkatan pendapatan Petani Stroberi sebesar Rp 110. Nilai dari thitung < ttabel yaitu $0,331<2,055$ dengan signifikansi sebesar $0,743>0,05$ yang berarti bahwa variabel Ipestisida tidak berpengaruh secara signifikan terhadap pendapatan petani stroberi.

4. Biaya $\mathrm{TK}\left(\mathrm{X}_{4}\right)$ 
Biaya tenaga kerja memiliki nilai koefisien sebesar 0,149. Hal ini berarti bahwa setiap penambahan Rp 1 maka akan meningkatkan pendapatan petani strobero sebesar Rp 1.490. Nilai dari thitung > ttabel yaitu 3,291>2,055 dengan signifikansi $0,003<0,05$ yang berarti bahwa TK berpengaruh pada pendapatan petani stroberi.

Tabel 14 Ringkasan Hasil Uji Hipotesis Faktor-Faktor Yang Mempengaruhi Produksi

\begin{tabular}{|c|c|c|c|}
\hline No. & Hipotesis & Signifikansi & $\begin{array}{l}\text { Kete } \\
\text { rangan }\end{array}$ \\
\hline 1 & $\begin{array}{l}\text { Luas lahan } \\
\text { berpengaruh } \\
\text { terhadap Produksi } \\
\text { Petani Stroberi di } \\
\text { Usahatani } \\
\text { Usahatani Sari } \\
\text { Buah Stroberi, }\end{array}$ & $\begin{array}{l}0,993> \\
0,05\end{array}$ & Ditolak \\
\hline 2 & $\begin{array}{l}\text { Umur berpengaruh } \\
\text { terhadap Produksi } \\
\text { Petani Stroberi di } \\
\text { Usahatani } \\
\text { Usahatani Sari } \\
\text { Buah Stroberi, }\end{array}$ & $\begin{array}{l}0,256> \\
0,05\end{array}$ & Ditolak \\
\hline 3 & $\begin{array}{l}\text { Modal berpengaruh } \\
\text { terhadap Produksi } \\
\text { Petani Stroberi di } \\
\text { Usahatani } \\
\text { Usahatani Sari } \\
\text { Buah Stroberi, }\end{array}$ & $\begin{array}{l}0,345> \\
0,05\end{array}$ & Ditolak \\
\hline 4 & $\begin{array}{l}\text { Tenaga Kerja } \\
\text { berpengaruh } \\
\text { terhadap Produksi } \\
\text { Petani Stroberi di } \\
\text { Usahatani } \\
\text { Usahatani Sari } \\
\text { Buah Stroberi, }\end{array}$ & $\begin{array}{l}0,372> \\
0,05\end{array}$ & Ditolak \\
\hline 5 & $\begin{array}{l}\text { Bibit berpengaruh } \\
\text { terhadap Produksi } \\
\text { Petani Stroberi di } \\
\text { Usahatani } \\
\text { Usahatani Sari }\end{array}$ & $\begin{array}{l}0,000< \\
0,05\end{array}$ & Diterima \\
\hline
\end{tabular}


6

\begin{tabular}{lll} 
Pupukberpengaruh & $0,201>$ & Ditolak \\
terhadap Produksi & 0,05 & \\
Petani Stroberi di & & \\
Usahatani & & \\
Usahatani Sari & \\
Buah Stroberi, & $0,134>$ & Ditolak \\
Pendidikan & 0,05 & \\
berpengaruh & \\
terhadap Produksi & \\
Petani Stroberi di & \\
Usahatani & \\
Usahatani Sari \\
Buah Stroberi, \\
\multicolumn{2}{c}{ Ttabel = $\mathbf{2 , 0 6 8}$}
\end{tabular}

Sumber: Data Primer, Diolah 2021

Berdasarkan hasil analisis dan pengujian hipotesis diketahui bahwa Luas $\operatorname{Lahan}\left(\mathrm{X}_{1}\right), \operatorname{Umur}\left(\mathrm{X}_{2}\right), \operatorname{Modal}\left(\mathrm{X}_{3}\right)$, Tenaga $\operatorname{Kerja}\left(\mathrm{X}_{4}\right)$, Pupuk $\left(\mathrm{X}_{6}\right)$, Pendidikan $\left(\mathrm{X}_{7}\right)$ tidak berpengaruh secara signifikan terhadap variabel Produksi $\left(\mathrm{Y}_{1}\right)$, yang artinya tidak memiliki pengaruh yang nyata terhadap faktor produksi. Sedangkan Faktor yang paling berpengaruh secara signifikan yaitu Bibit $\left(\mathrm{X}_{5}\right)$, yang artinya bahwa Bibit memiliki pengaruh yang nyata terhadap Produksi pada Usahatani Sari Buah Stroberi,
Desa Pandanrejo, Kecamatan Bumiaji, Kota Batu.

Tabel 15. Ringkasan Hasil Uji Hipotesis Faktor-Faktor Yang Mempengaruhi Pendapatan

\begin{tabular}{llll}
\hline No. & hipotesis & signifikansi & $\begin{array}{l}\text { Kete } \\
\text { rangan }\end{array}$ \\
\hline 1 & Biaya Bibit & $0,052>$ & Ditolak \\
& Berpengaruh & 0,05 & \\
gnifikan & & \\
& terhadap & & \\
& pendapatan & & \\
& petani di & \\
& Usahatani \\
& Usahatani Sari & & \\
& Buah Stroberi, , &
\end{tabular}




$\begin{array}{llll}2 & \text { Biaya Pupuok } & 0,129> & \text { Ditolak } \\ \text { Berpengaruh } & 0,05 & \\ \text { ignifikan terhadap } & & \\ \text { pendapatan petani } & & \\ \text { di Usahatani } & & \\ \text { Usahatani Sari } & & \\ \text { Buah Stroberi, } & & \\ \text { Biaya Pe3stisida } 0,743> & \text { Ditolak } \\ \text { Berpengaruh } 0,05 & \\ \text { ignifkan terhadap } & \\ \text { pendapatan petani } & \\ \text { di Usahatani } & \\ \text { Usahatani Sari } & \\ \text { Buah Stroberi, } & \\ \text { Biaya TTK } 0,003< & \text { Diterima } \\ \text { Berpengaruh } & 0,05 & \\ \text { sinifikan terhadap } & \\ \text { pendapatan petani } \\ \text { di Usahatani } \\ \text { Usahatani Sari } \\ \text { Buah Stroberi, }\end{array}$

\section{Ttabel $=\mathbf{2 , 0 5 5}$}

Sumber: Data Primer, Diolah 2021

Berdasarkan tabel 15 hasil analisis dan pengujian hipotesis diketahui bahwa Biaya $\operatorname{Bibit}\left(\mathrm{X}_{1}\right)$, Biaya $\operatorname{Pupuk}\left(\mathrm{X}_{2}\right)$, Biaya Pestisida $\left(X_{3}\right)$, tidak berpengaruh secara signifikan terhadap Pendapatan $\left(\mathrm{Y}_{2}\right)$, yang berarti bahwa biaya bibit biaya pupuk dan biaya pestisida tidak mememiliki pengaruh yang nyata terhadap Pendapatan Usahatani Sari Buah Stroberi, Sedangkan faktor yang paling berpengaruh secara signifikan terhadap Pendapatan $\left(\mathrm{X}_{2}\right)$ yaitu variabel Biaya Tenaga Kerja $\left(\mathrm{X}_{4}\right)$ yang artinya

\begin{tabular}{llr}
\hline Komponen & \multicolumn{2}{c}{ Rupiah (Rp) } \\
\hline Biaya Tetap & \multicolumn{2}{r}{} \\
Penyusutan Alat & Rp & 15.000 \\
Pajak & Rp & 512.000 \\
Biaya TK & Rp & 41.628 .000 \\
Total BT & Rp & $\mathbf{4 2 . 1 5 5 . 0 0 0}$
\end{tabular}

bahwa Biaya TK memiliki pengaruh yang nyata terhadap Pendapatan petani stroberi

\section{Analisis Kelayakan Usahatani Sari Buah Stroberi, Desa Pandanrejo, Kecamatan Bumiaji, Kota Batu \\ Berikut ini adapun perhitungan biaya yang dikeluarkan oleh 30 petani stroberi Adapun kompenen dan jumlah Biaya yaitu sebagai berikut: \\ Tabel 16. Biaya Tetap Dan Biaya Variabel Usahatani Sari Buah Stroberi.}


Biaya Variabel

\begin{tabular}{lcr} 
Biaya Bibit & Rp & 13.020 .000 \\
Biaya Pupuk & $\mathrm{Rp}$ & 22.620 .000 \\
Biaya Pestisida & $\mathrm{Rp}$ & 2.160 .000 \\
Total Biaya Variabel & Rp & $\mathbf{3 7 . 8 0 0 . 0 0 0}$ \\
\hline Biaya Total (Total & & \\
Cost/Tc) & Rp & $\mathbf{7 9 . 9 5 5 . 0 0 0}$ \\
\hline
\end{tabular}

\section{Pendapatan \\ Usahatani Sari \\ Buah Stroberi, \\ Desa \\ Pandanrejo, Rp $\quad 162.419 .000$ \\ Kecamatan \\ Bumiaji, Kota \\ Batu}

Sumber: Data Primer, Diolah 2021

$\begin{array}{rlcr}\text { Berdasarkan } & \text { tabel } & 16 & \text { diatas } \\ \text { diddapatkan nilai } & \text { BT } & \text { sebesar } & \text { Rp }\end{array}$
79.955.000, dengan perincian Biaya Tetap yaitu penyusutan alat sebesar Rp 15.000, Pajak sebesar 512.000, Biaya TK sebesar Rp. 41.628.000. Dengan demikian maka total BT sebesar Rp. 42.155.000. Sedangkan Biaya Variabel terdiri dari bibit senilai $\mathrm{Rp}$ 13.020.000, Pupuk senilai Rp. 22.620.000, Biaya Pestisida sebesar 2.160.000, dengan demikian maka total biaya variabel yaitu $\mathrm{Rp}$ 37.800.000. Pendapatan 30 Petani Stroberi di Usahatani Sari Buah Stroberi, Desa Pandanrejo, Kecamatan Bumiaji, Kota Batu, yaitu sebesar Rp 162.419.000.

Analisis RC ratio dalam usahatani menunjukan perbandingan antara nilai uang yang dikeluarkan dengan nilai yang diperoleh yang memiliki tujuan untuk mengetahui kelayakan dari usahatani yang dilaksanakan. Selain itu $\mathrm{RC}$ rasio juga merupakan perbandingan antara penerimaan dengan pengeluaran usahatani. Pada dasarnya sebuah usaha dapat dikatan layak untuk dijalankan apabila nilai $\mathrm{RC}>1$. Dengan Rumus

$$
R C \text { Rasio }=\frac{\mathrm{TR}}{\mathrm{TC}}
$$

Adapun kriteria penilaian kelayakan usaha yaitu

a. R/C kurang dari 1, maka usaha rugi

b. R/C lebih dari 1, maka usaha menguntungkan.

c. R/C sama dengan 1, maka usaha berada pada titik impas (Break Event Point).

$R C$ Rasio $=\frac{\operatorname{Rp} 162.419 .000}{\operatorname{Rp} 79.955 .000}=2,03$

Nilai R/C rasio adalah 2,03, yang berarti lebih dari 1. Dengan demikian diketahui bahwa secara ekonomis Usahatani Sari Buah Stroberi, Desa Pandanrejo, Kecamatan Bumiaji, Kota Batu yang dilakukan secara ekonomis menguntungkan, hal ini di buktikan dengan nilai $\mathrm{R} / \mathrm{C}$ sebesar 2,03. Dengan demikian maka diketahui bahwa tingkat perhitungan RC Rasio diatas sebesar 2,03 maka dikatakan bahwa 
Usahatani Sari Buah Stroberi, Desa Pandanrejo, Kecamatan Bumiaji, Kota Batu layak untuk dijalankan

\section{KESIMPULAN}

1.Faktor yang mempengaruhi Produksi dalam penelitian ini terdiri dari Luas $\operatorname{Lahan}\left(\mathrm{X}_{1}\right), \operatorname{Umur}\left(\mathrm{X}_{2}\right), \operatorname{Modal}\left(\mathrm{X}_{3}\right)$, Tenaga $\operatorname{Kerja}\left(\mathrm{X}_{4}\right)$, Bibit $\left(\mathrm{X}_{5}\right)$, Pupuk $\left(\mathrm{X}_{6}\right)$, Pendidikan $\left(\mathrm{X}_{7}\right)$ diketahui bahwa variabel yang berpengaruh signifikan terhadap Produksi pada Usahatani Sari Buah Stroberi, Desa Pandanrejo, Kecamatan Bumiaji, Kota Batu yaitu Bibit $\left(\mathrm{X}_{5}\right)$ yang berarti bahwa Bibit memiliki pengaruh yang nyata pada Usahatani Sari Buah Stroberi, Desa Pandanrejo, Kecamatan Bumiaji, Kota Batu. Sedangkan Luas Lahan, Umur, Modal, Tenaga Kerja dan Pupuk, Pendidikan tidak berpengaruh secara signifikan

\section{DAFTAR PUSTAKA}

Ambarsari, W., Ismadi, V. D. Y. B., \& Setiadi, A. (2014). Analisis Pendapatandan Profitabilitas Usahatani Padi.Agromedia, 6(2), 27.

Amin, S. (2014). Faktor-faktor yang mempengaruhi produksi pala di Kecamatan Pasie Raja Kabupaten Aceh Selatan. Agromedia, 2(6).

Amin, S. (2015). Berkebun Stroberi secara Komersial. Jakarta: Penebar Swadaya. Agromedia, 4(3).

Arifin Zainol, R. A. (2020). Teori

Keputusan Dan Pembangunan

Pertanian Berkelanjutan. 1, 1-8.

Http://Agbsosek.Blogspot.Co.Id/2015/1

1/Makalah-Pertanian-

Berkelanjutan.Html

Ariyani, D. M. A., Santoso, S. I., \& Setiadi, A. (2017). Analisis Profitabilitas Usaha tani Jambu Biji Getas Merah Di Kabupaten Kendal. Agromedia,35(2),
1. Faktor yang mempengaruhi Pendapatan dalam penelitian ini terdiri dari Biaya Bibit $\left(\mathrm{X}_{1}\right)$ dengan signifikansi 0,052 $>0,05$,Biaya $\operatorname{Pupuk}\left(\mathrm{X}_{2}\right)$ dengan nilai sebesar 0,129>0,05,Biaya Pestisida $\left(\mathrm{X}_{3}\right)$ 0,743 > 0,05,Biaya Tenaga Kerja $\left(\mathrm{X}_{4}\right)$ dengan signifikansi $0,003<0,05$, diketahui bahwa variabel yang berpengaruh signifikan terhadap Produksi pada Usahatani Sari Buah Stroberi, Desa Pandanrejo, Kecamatan Bumiaji, Kota Batu yaitu Biaya Tenaga Kerja $\left(\mathrm{X}_{4}\right)$,

2. Dari hasil perhitungan analisis kelayakan usaha yang dilakukan pada Usahatani Sari Buah Stroberi, Desa Pandanrejo, Kecamatan Bumiaji, Kota Batu, usaha yang dijalankan layak dari hasil perhitungan Return Cost Rasio dengan nilai $2,03>1$.

$10-18$.

Boediono, B. (1996). Perpajakan Indonesia. Jilid I. Jakarta : Kawula Muda.

Bryan Lowes Leslie Davies \& Christopher Pass. (1994). Collins Kamus Lengkap Ekonomi Edisi Kedua, Erlangga, Jakarta. Agromedia, 3(2).

Budiman, Supriatin dan Saraswati, D. (2008). Berkebun Stroberi secara Komersial. Jakarta: Penebar Swadaya. Agribisnis, 4(3).

Darwis, V. (2007). Budidaya, Analisis Usahatani, dan kemitraan StroberiTabanan, Bali, Pusat.

Efendi, Y. (2016). Analisis Usahatani Tomat(Licopersicon Esculentum Mill) Di Desa Mandesan KecamatanSelopuro Kabupaten Blitar. Viabel Pertanian, 10(2), 51-61.

Hanani, N., Asmara, R., \& Hanafi, A. A. (2012). Analysis ofBusiness And Feasibility In The Drink of Agroindustry Extract Apple. 
Agricultural

Socio-Economics

Journal, 12 (1), 13

KEMENRISTEK. (2010). Kementerian Riset dan Teknologi.Teknologi Pangan DanAgroindustri.TerhubungBerkala]Htt p://Www.Warintek.Ristek.Go.Id.[16 Februari 2012].

Kurnia, A. (2015). Petunjuk Praktis Budi Daya Stroberi. Jakarta. AgroMediaPustaka.

Luntungan, A. Y. (2019). Analisis Tingkat Pendapatan Usaha Tani Tomat Apel.Di Kecamatan Tompaso Kabupaten Minahasa. jurnal pembangunan.

Muchtadi. (2016). Pengetahuan dan Pengolahan Bahan Nabati. Departemen Teknologi Hasil PertanianIPB: Bogor.

Novitaningsih, T., Imam Santoso, S., \& SETIADI, A. (2018). Analisis Profitabilitas Usahatani Padi Organik, di Paguyuban Al-Barokah Kecamatan Susukan Kabupaten Semarang. Jurnal Mediagro Fakultas Pertanian Universitas Wahid Hasyim Semarang, 14(1).

Perkins, F. (1994). Analisis Pendapatan Usahatani Bunga Potong (Studi Kasus Petani Bunga Krisan Putih, di Kelurahan Kakaskasen Dua Kecamatan Tomohon Utara Kota Tomohon). Practical Cost Benefit Analysis. Macmillan Education Australia PTY LTD. Australia. Pangemanan, L., Kapantow, G., \& Watung, M. (2011)., 7(2), 5-14.

Reksoprayitno, S. (2016). Ekonomi Makro. Edisi BPFE.UGM.Yogyakarta.

Rukmana, H. R. (2017). Stroberi Budidaya dan Pascapanen. Kanisius. Yogyakarta.

Soekartawi. (2008). Agroindustri Dalam Perspektif Sosial Ekonomi. Raja Grafindo Persada.Jakarta.
Sudaryati, E. (2004). Faktor-Faktor Yang Mempengaruhi Produksi Kopi Rakyat Di Kabupaten Temanggung. (Studi Kasus Di Kecamatan Candiroto, Kabupaten Temanggung) (Doctoral Dissertation, Program Pascasarjana Universitas Diponegoro).

Sugiono. (2013). Metodologi Penelitian Kuantitatif,Kualitatif dan $R \& D$. (Bandung:ALFABETA).

Suprihatin Budiman dan Desi saraswati. (2017). Berkebun Stroberi Secara Komersial. Penebar Swadaya.Penebar Swadaya. Jakarta.

Wirakusumah. (2017). Jus sehat Buah \& Sayuran. Jakarta.Penebar Swadaya. 